Veja y el centenario de 1889. Representaciones de la República en la vuelta a la democracia en Brasil

Florencia Lederman

Question, Vol. 1, N. 57, e024, enero-marzo 2018. ISSN 1669-6581

http://perio.unlp.edu.ar/ojs/index.php/question/article/view/4359

FPyCS | Universidad Nacional de La Plata

La Plata | Buenos Aires | Argentina

Recibido: 05-09-2017 Aceptado: 21-11-2017

Cita sugerida: Lederman, F. (2018). Veja y el centenario de 1889. Representaciones de la República en la vuelta a la democracia en Brasil. Question, 1(57), e024. doi: https://doi.org/10.24215/16696581e024

\title{
Veja y el centenario de 1889. Representaciones de la República en la vuelta a la democracia en Brasil
}

\author{
Veja and the centenary of 1889. Representations of the Republic in the \\ return to democracy in Brazil
}

Florencia Lederman

Grupo de Estudios de Sociología Histórica de América Latina; Instituto de Estudios de América Latina y el Caribe; Facultad de Ciencias Sociales; Universidad de Buenos Aires (Argentina) florlederman@gmail.com

\section{Resumen}

En 1989, en Brasil, se conmemoró el centenario de la proclamación de la República (15 de noviembre de 1889). Ya en democracia, aunque con un presidente electo indirectamente. En 1985, Tancredo Neves fue elegido por junta electoral, luego del fracaso la campaña Diretas Já!. Su temprano fallecimiento colocó a su vice, José Sarney en la presidencia. En este contexto, la revista Veja publicó un número especial dedicado al aniversario. 
Durante la dictadura militar brasileña (1964-1985), Veja defendió el lugar de Brasil en América Latina y de esta manera al gobierno de la dictadura, apoyando los planes de industrialización, exportaciones y préstamos a los países del continente, porque sus intereses estaban en consonancia con los proyectos militares, a través de los cuales engrosaba su capital económico. La revista buscó mostrar una postura neutral cuando en realidad se posicionó en el lugar de la búsqueda de consensos y la articulación de intereses. En este sentido, sostenemos que la publicación semanal funcionó como un órgano de representación de los intereses de las elites empresarias y militares, de las derechas.

El objetivo de este artículo es analizar las representaciones de la República brasileña publicadas por Veja en ese número dedicado a la conmemoración del aniversario de la proclamación de la república, prestando especial atención a la posición de la revista sobre la incipiente democracia brasileña, teniendo en cuenta su probado apoyo a la mencionada dictadura.

Palabras clave: Brasil; República; revista Veja; centenario.

Abstract

In 1989, in Brazil, the centenary of the Proclamation of the Republic was commemorated (november 15, 1889). Already in democracy, although with a president-elect indirectly. In 1985 , Tancredo Neves was elected by the electoral board, after the failure of the Diretas Já! Campaign. His early death placed his vicepresident, José Sarney in the presidency. In this context, Veja magazine published a special issue dedicated to the anniversary.

During the Brazilian military dictatorship (1964-1985), Veja defended the place of Brazil in Latin America and in this way the government of the dictatorship, supporting industrialization plans, exports and loans to the countries of the continent, because their interests were in consonance with the military projects, through which it enlarged its economic capital. So, the magazine sought to show a neutral stance when in fact it positioned itself in the place of the search for consensus and the articulation of interests. In this sense, we maintain that the weekly publication functioned as an organ representing the interests of the business and military elites of the right.

The objective of this article is to analyze the representations of the Brazilian Republic published by Veja in that issue dedicated to the commemoration of the anniversary of the proclamation of the republic, paying special attention to the position of the magazine on the incipient Brazilian democracy, taking into account his proven support for the aforementioned dictatorship.

Keywords: Brazil; republic; Veja magazine; centenary. 
1989 fue un año convulsionado a nivel mundial. La caída del muro de Berlín marcó un antes y un después en la historia de la lucha por la hegemonía y el poder global. La desaparición de la Unión de Repúblicas Socialistas Soviéticas (URSS) dos años más tarde le dio a Estados Unidos su preciado lugar de potencia unipolar. Y el mismo año, George Bush (1) asumió la presidencia de ese país.

En América Latina, 1989 también fue un año particular. Hubo elecciones presidenciales a lo largo y ancho del continente. En la Argentina, Carlos Menem encabezó la profundización del modelo neoliberal en el país (2). En Paraguay, se celebraron las primeras elecciones democráticas en treinta y cinco años, luego de la caída del dictador Alfredo Stroessner (3). En Venezuela, irrumpió el "caracazo", una serie de manifestaciones populares durante el gobierno de Carlos Andrés Pérez (4).

En Brasil, se conmemoró el centenario de la Proclamación de la República (15 de noviembre de 1889), ya en democracia, aunque con un presidente electo indirectamente. En 1985, Tancredo Neves (5), fue elegido por junta electoral, luego del fracaso parlamentario de la campaña Diretas Já!. Su temprano fallecimiento colocó a su vice, José Sarney (6) en la presidencia (Skidmore, 1991; O'Donnell, 1994; Martins, 1994; Weffort, 1989; Sader, 2001).

En este contexto, la revista Veja, publicada por la Editora Abril, sacó un número especial dedicado al aniversario. La revista se posicionó en el lugar de la búsqueda de consensos y la articulación de intereses. En este sentido, sostenemos que la publicación semanal, funcionó como un órgano de representación de los intereses de las elites empresarias y militares, de las derechas. Y, no sólo como un medio de comunicación, sino como un actor político relevante y, especialmente como un intelectual orgánico de las clases dominantes (Gramsci, 1986), representadas por la alianza entre militares, burocracia y empresarios (Bresser Pereira, 1978; Pucciarelli, 2004).

Durante la dictadura militar brasileña (1964-1985), Veja defendió el lugar de Brasil en América Latina y de esta manera al gobierno de la dictadura, apoyando los planes de industrialización, exportaciones y préstamos a los países del continente, porque sus intereses estaban en consonancia con los proyectos militares, a través de los cuales engrosaba su capital económico.

En el último número de 1968, Veja destaca los grandes logros llevados adelante por la dictadura y deja claramente asentada su posición de contribuir con ese proyecto de país.

Acreditamos que 1969 será mais um ano importante na marcha para o desenvolvimento. Acompanhamos com entusiasmo o progresso já produzido pelas novas rodovias, usinas, indústrias e escolas que brotam no País inteiro. E confiamos em que o trabalho honesto de dezenas de milhões de brasileiros -dentro de um clima de ordem e seriedade- continuará 
contribuindo para o crescimento da Nação e o bem-estar de todos. A Abril está empenhada em colaborar neste esforço com todos os recursos que possui. (...) O mundo espera muito do Brasil e o Brasil, de cada brasileiro. VEJA procurará cumprir sua parte, informando com precisão, rapidez, imparcialidade e entusiasmo. Carta del editor (25 de diciembre de 1968). Veja, p. 13.

El objetivo de este artículo es analizar las representaciones de la República publicadas por Veja en ese número dedicado a la conmemoración del aniversario de la proclamación de la república, prestando especial atención a la posición de la revista sobre la incipiente democracia brasileña, teniendo en cuenta su, ya aludido, apoyo al gobierno de facto.

La metodología utilizada es cualitativa, basada en el análisis documental y la comparación analítica. Se apela a la comparación constante: explicar acontecimientos tanto similares como contrastantes, a efectos de descubrir eventuales regularidades (sobre la representación de la república) que tornen posible ofrecer generalizaciones explicativas y señalar especificidades históricas.

Para la identificación de los temas emergentes y recurrentes, trabajamos con los aportes del análisis crítico del discurso (Van Dijk, 2002) en tanto entendemos que el lenguaje se manifiesta como una "forma de práctica social, centrándose en los modos en que la dominación política y social se reproduce a través de los textos" (Marradi, Archenti y Piovani, 2010: 297). Es decir, situando al texto en el contexto social que otorga significaciones al discurso.

Veja pertenece al grupo editorial Abril, hoy uno de los más importantes de Brasil, fundado por Víctor Civita hacia 1950. La Editora Abril tiene sus orígenes en Italia, Estados Unidos y Argentina. Civita, hijo de italianos emigrados a Estados Unidos, abrió la editorial a instancias de su hermano César, quien era dueño de la Editorial Abril en Buenos Aires. En la década de 1950, la editorial ya era famosa por la publicación de historietas (especialmente el Pato Donald y otros personajes de Disney) y algunos libros (las colecciones, también especializadas en literatura infantil, incluían personajes de Disney y otras historias estadounidenses como las de Tarzán, Dick Treacy, entre otros). César, le propone a su hermano dirigir la filial de Abril en Brasil. Las primeras publicaciones también fueron historietas del Pato Donald. Ante la escasez de este tipo de revistas en Brasil, el simpático pato tuvo gran éxito rápidamente (Scarzanella, 2016).

Roberto, hijo de Víctor, volvió a los Estados Unidos a perfeccionarse en la industria gráfica. Luego de su experiencia como pasante en la revista Time (7), propuso la creación de Veja. Fue la primera revista de información general de la editorial, que ya contaba con otras publicaciones exitosas para diferentes segmentos del mercado: Claudia, Quatro Rodas y Realidade. Roberto Civita, como director de la revista de información, estuvo más involucrado en cuestiones políticas que su padre, y opinaba que el papel de la prensa era cambiar la cabeza de las personas y no presionar a los ministros del gabinete (Mira, 1997). 
Veja lanzó su primer número en septiembre de 1968, tres meses antes de la proclamación del Al-5 (8), siguiendo el modelo de 'news magazine' de Estado Unidos. Con el tiempo, se convirtió en una de las revistas dirigidas a la clase media con mayor circulación (Villalta, 2002; Valle, 2012). Su primer número fue un éxito de ventas con 700.000 ejemplares. Según su director, su objetivo era el de ser la más respetada revista de Brasil y la principal publicación del país, no solamente en términos económicos sino también "em insistência na necessidade sua de concertar, reformular, repensar e reformar o Brasil. Essa é a missão da revista. Ela existe para que os leitores entendam melhor o mundo em que vivemos" (9).

Según Mira (1997), en sus primeros años, Veja, tuvo una posición crítica con la dictadura militar. Dice la autora que, por su posición liberal, la revista no podía aceptar el cierre del Congreso, la suspensión de los derechos civiles, la censura. A partir de 1975 esa situación cambió. Se produjo la renuncia de su editor, Mino Carta (10), por presión del régimen, y Veja viró hacia una postura más conservadora y cercana al gobierno de facto. (11) Sin embargo, desde el punto de vista de las políticas económicas de desarrollo y de la política exterior, Veja tuvo una gran afinidad con la dictadura desde sus primeros números. En este sentido, coincidimos con Rautenberg (2011) en que "Veja contribui com a ditadura militar moldando, formando preferências e construindo adaptações às 'regras do jogo capitalista', porque via através desta uma maneira de ver consolidada sua política partidária e concretizada suas estratégias de poder" (p. 74).

Hacia 1989, Veja profundiza su perfil capitalista neoliberal, contribuyendo con la difusión de transformaciones sociales y culturales acompañadas de la políticas económicas devenidas de los postulados del Consenso de Washington (Giordano, 2017) que, "estaban basados en una lógica de mercado caracterizada por la apertura y disciplina macroeconómica" (Rangel y Garmendia, 2012: 43) que implicaban un ajuste estructural y la reforma del Estado. El Consenso de Washington, marcó desde fines de los años '80, la profundización de la etapa neoliberal en América Latina, iniciada por las dictaduras institucionales de las FFAA en la década de los 70 .

Los intereses de la revista, entonces, se relacionan con las privatizaciones, la apertura de capitales, oligopolización de la economía (Silva, 2005). Veja fue tanto un proyecto editorial como político. La revista fue financiada por grandes empresas nacionales y multinacionales, con lo cual su alianza con la burguesía y el empresariado era indiscutible.

Es sabido que los medios masivos son formadores de opinión en su representación de la realidad. Los diarios de difusión masiva son considerados creadores de marcos para ver el mundo social, generadores y transmisores de ideologías, de miradas alternativas sobre la sociedad y sus problemas (Sidicaro, 1993). Asimismo, los medios colaboran fuertemente con la creación de la agenda de temas que una sociedad pone en discusión (Blaustein y Zubieta, 1998). En esta misma línea, Goldstein (2017) retoma la teoría del agenda setting y sostiene 
que los medios no tienen éxito en decirles a las personas qué pensar, pero son eficientes en determinar aquello sobre lo cual pensar.

Diversos trabajos afirman que los medios de comunicación son actores políticos. Borrat sostiene que el ámbito de actuación de los periódicos de información general es el de la influencia en el poder institucional. "El periódico pone en acción su capacidad para afectar el comportamiento de ciertos actores en un sentido favorable a sus propios intereses: influye sobre el gobierno, pero también sobre los partidos políticos, los grupos de interés, los movimientos sociales, los componentes de su audiencia" (1989: 67). En la misma línea, Borrelli entiende que las publicaciones son "vehículos activos destinados a la conformación de espacios sociales, la construcción de públicos, la legitimación de corrientes de opinión, la influencia concreta en las decisiones políticas y de interés público" (2011: 26). El autor hace referencia a las empresas editoras de grandes diarios argentinos como Clarín, La Nación, La Opinión, La Prensa y La Razón, quienes privilegiaron sus propios intereses frente a la dictadura iniciada en 1976, y se adaptaron a las demandas del poder político. Sostenemos que estas ideas pueden trasladarse a nuestro propio corpus, la revista Veja, entendiéndola como actor político.

Rautenberg, en su trabajo sobre la relación entre Veja y las empresas de construcción civil, entiende a la revista, en términos gramscianos, como un aparato privado de hegemonía "na busca/construção do consenso e também como lugar de articulação de interesses políticos e econômicos" (2011: 15). En este sentido es que Gramsci (2008) también afirma que los diarios o las revistas pueden ser entendidos como partidos políticos (12) por su función dirigente. Silva (2005) sostiene que eso sucede porque los períodicos tienen una doble función: informar y opinar: "a necessidade de ser informado faz com que muitas vezes se receba opinião e programa de ação partidário como sendo mera informação" (p. 31).

Gramsci (1986: 360) afirma que "para algunos grupos sociales el partido político no es otra cosa que el modo propio de elaborar su propia categoría de intelectuales orgánicos". (13) Silva agrega que el rol de la prensa en cuanto intelectual colectivo es el de formular, organizar y gerenciar. "É, portanto, uma ação de direção e de dirigente, e a formulação se dá sempre em conjunto com outro agentes" (2005: 32).

En este sentido, entendiendo a la prensa como actor político, podemos reunir la idea de ver a la revista como partido político y a la vez como intelectual orgánico. Como partido representa a un grupo social, el mismo grupo (clases dominantes) la crea como intelectual para sostener su hegemonía.

Así es que, partiendo de estas idea sobre el rol de la prensa y de Veja en particular, abordaremos las representaciones de la República en el contexto del centenario de su Proclamación (14). 


\section{La República según la Veja de 1889}

La edición especial de Veja se publicó el 20 de septiembre de 1989, como un suplemento extra del número 1097, pero estaba fechado el 20 de noviembre de 1889. La intención fue redactar un número de la revista como si ella se hubiera publicado un siglo antes, mas con un lenguaje actual porque si no "sería muy extraño para los lectores de hoy" (A semana há cem anos. 20 de septiembre de 1989, Veja, parr. 7). Además, dice la carta que,

não se buscou apenas contar como foi derrubada a Monarquia e estabelecido o regime republicano naquele longínquo 15 de novembro, mas também dar um panorama fidedigno de cómo era o país, seus costumes, economia, arte, esporte, sua vida cotidiana.

A semana hácem anos (20 de septiembre de 1989), Veja, parr. 1.

El editorial sostiene que no hay acuerdo sobre los hechos de ese 15 de noviembre y que lo único claro es que aquel día "Brasil despertó monárquico y se fue a dormir republicano".

La crisis del Imperio había comenzado unos veinte años antes de la proclamación (sucedida el 15 de noviembre de 1889). Sucintamente mencionamos algunos de los factores que llevaron a esa situación: el fin de la esclavitud, el advenimiento de movimientos republicanos que proponían una revolución popular como el camino para llegar a la república, las tensiones entre el Estado y la Iglesia y la propia participación de militares en el gobierno imperial que luego se levantaron contra este. Además, la delicada situación económica de la monarquía, debido a una crisis de la deuda externa y el crecimiento del déficit fiscal. Por último, entre los factores de la crisis se encuentra la falta de integración territorial lo que dificultaba el desarrollo y las comunicaciones con el interior del país (Fausto, 2010).

Una nota donde se hace una crónica del embarque al exilio de la familia imperial (15), dos días después de la proclamación de la república, representa la idea de la república venidera.

\footnotetext{
O império findou sem que ninguém o defendesse ou chorasse. Acabou porque era uma forma de governo anacrônica, exaurida, incapaz de oferecer perspectivas de melhorar ao país, ampliando os direitos dos cidadãos. Agora, é a hora da República o regime que pode democratizar o Brasil. O outono do patriarca. (20 de septiembre de 1989), Veja, parr.19.
}

A pesar que en 1989, ya habían pasado cuatro años del fin de la dictadura militar, la transición en Brasil aun estaba en proceso. Ese año se llevaron a cabo las primeras elecciones presidenciales con voto directo desde el fin de la dictadura y las primeras también en la que un 
civil accedía a la presidencia mediante el voto desde 1960 (como se mencionó más arriba, José Sarney llegó a la primera magistratura por el fallecimiento de Neves).

Con estas elecciones comienza el fin de la transición a la democracia. Una transición lenta y muy prolongada, que comenzó en 1974 con la apertura promovida por el general Ernesto Geisel (16), y fue acompañada muy de cerca por los militares. En términos de O'Donnell (1994), Brasil vivió una transición pactada que, a pesar del regreso de los civiles al poder en 1985, recién concluye en el año del centenario de la proclamación de la República. Así, en la vinculación entre democracia, entendida en este artículo como una ampliación de derechos civiles, y república, la oposición a ésta no sería solo la monarquía, sino, pensando desde 1989, también la dictadura.

Este número también incluye un 'reportaje' a Rui Barbosa (17), primer ministro de economía de la República que, según la revista, se había convertido en republicano solo unos días antes de los acontecimientos. Tanto las preguntas como las respuestas de la entrevista fueron redactadas por Veja, dado que no es un reportaje real, sino reconstruido a partir de documentos históricos.

En las primeras dos preguntas, Veja se refiere a la república de formas muy diferentes, hasta contradictorias podríamos sugerir.

\footnotetext{
Essa adesão ao credo republicano às vésperas da proclamação não pode the valer a acusação de oportunismo?

Crepúsculo do filósofo. (20 de septiembre de 1989), Veja, parr 4. (Las itálicas son nuestras).

Antes de apoiar o movimento republicano, que tipo de monarquista o senhor era? Crepúsculo do filósofo. (20 de septiembre de 1989), Veja, parr 5. (Las itálicas son nuestras).
}

Aunque cuando se nombra la república todos tenemos una noción de qué es de lo que se está hablando, no hay una única idea ni definición de ella. Se acuerda que es un sistema de gobierno que se caracteriza por la división de poderes, sistema de controles (horizontales y verticales) a representantes del pueblo y funcionarios del Estado (O'Donnell, 1997). Sin embargo, no deja de ser "un campo de batalla" (Rinesi, 2015). Y "es a través y no a pesar de esa batalla que la república se hace más fuerte, más vital y más rica" (Rinesi, 2015: 92). La pregunta que aquí surge es si esa batalla por su definición puede ir desde la abstracción de una creencia, como propone Veja en la primera pregunta, hasta lo concreto, la acción que implica un movimiento, como en la segunda interrogación.

La primera idea de república con la que nos encontramos, entonces, oscila entre lo intangible, lo ideal y hasta lo religioso, y lo concreto, un movimiento que, en el caso de Brasil no fue ni revolucionario, ni ciudadano. Fue un movimiento militar que derrocó a una monarquía débil e instauró una república oligárquica (18). 
Más adelante en la 'entrevista', aparece la pregunta por la posibilidad de la restauración monárquica. Un tema que, cien años después, seguía siendo de suma actualidad en Brasil, hasta el punto de haber establecido la fecha para un plebiscito que definiría el sistema de gobierno.

El 5 de octubre de 1988 fue promulgada la nueva Constitución, luego de más de un año de debates en la Asamblea Constituyente (conformada en febrero de 1987). A pesar del fortalecimiento de derechos civiles y políticos, la Constitución dejó algunos temas, no menores, sin resolver: "la propia definición del sistema presidencialista de gobierno y hasta la de la forma republicana quedaron sujetas a un plebiscito pautado para el día 7 de septiembre de 1993" (Fausto, 2010: 525), en el 171 aniversario de la independencia de Brasil.

VEJA: Se o imperador tiver apoio das realezas europeias, o senhor considera possível a restauração monárquica?

Rui Barbosa: A idéia de restauração é sebastianismo ou ignorância de especuladores ou tolos. Ouro Preto é abominado no Brasil. D. Pedro está sendo explorado pelos antigos diplomatas imperiais. As pretensões à ingerência das monarquias europeias no Brasil são simplesmente ridículas. A República brasileira terá por si a aliança ofensiva e defensiva da América inteira. Crepúsculo do filósofo (20 de septiembre de 1989), Veja, parr 17.

No solamente se pone de manifiesto un debate que, es de larga data, sino que se observa el lugar que ocupa Brasil, desde el punto de vista brasileño (en este caso específicamente de Veja), en América Latina o América entera como dice el 'entrevistado'. La noción de la importancia de Brasil, ese ufanismo (19) de origen, se revela en las representaciones de la república de la revista.

Ya hacia el final de la entrevista, Veja le pregunta al ministro sobre el proyecto económico de su gobierno. ¿Cómo resolver el problema de la deuda? ¿Cuál será el papel de la inversión privada en la era republicana?

La situación financiera heredada de la monarquía era compleja. Una alta deuda externa que en el curso de la primera década se agravó, aumentando el déficit público. Esta situación comenzó a resolverse hacia fines del siglo XIX con la toma de más deuda que ponía a Brasil es una muy delicada situación (Fausto, 2010).

VEJA: Qual receita o senhor oferece para resolver esse problema da dívida? Enxugar a máquina estatal?

Rui Barbosa: Cortemos energicamente nas despesas. Eliminemos as repartições inúteis. Estreitemos o âmbito ao funcionalismo, reduzindo o pessoal e remunerando-lhe melhor o serviço. Moralizemos a administração, norteando escrupulosamente o provimento de cargos do Estado pela competência, pelo merecimento, pela capacidade. Cinjamonos, na criação de serviços novos, à necessidade absoluta. Fujamos do filhotismo republicano, 
transformação imoral e funesta do antigo nepotismo monárquico. Se procedermos assim, teremos meio caminho vencido para a reforma das nossas finanças, a reconstituição de nosso crédito e a fecundação das nossas forças vitais. Crepúsculo do filósofo (20 de septiembre de 1989), Veja, parr 20.

Si recordamos que este reportaje está situado en los albores de la república, se sugiere aquí una nueva forma de pensarla. La república está representada en el achicamiento del Estado. Idea calcada de las políticas neoliberales que comenzaron a ser implementadas por Brasil y otros países de la región en el momento en que efectivamente se publica esta nota: 1989. Igualmente, no debemos perder de vista que la corriente ideológica que primó en la instauración del nuevo régimen en 1889 fue el liberalismo (Carvalho, 2008), lo que, en parte, explica esta continuidad.

En esta nueva transición, la situación económica era, otra vez, compleja. En 1985 el escenario era relativamente estable. Menos grave que años anteriores. Sin embargo, la inflación llegó a $235,5 \%$ durante ese año. Como una forma de solucionar el problema de la inflación se elaboró el Plan Cruzado en 1986 (Fausto, 2010).

Para 1990, Brasil estaba en hiperinflación debido a la crisis fiscal, producto, entre otras cosas, de la nacionalización de la deuda privada entre 1981 y 1983. El plan de estabilización (Plan Collor) adoptado por el nuevo gobierno, asumido en marzo de 1990, tenía entre sus principales medidas un ajuste fiscal, congelamiento de precios, liberalización del comercio exterior y privatizaciones (Bresser Pereira y Nakano, 1991).

El escenario económico y las estrategias implementadas para la solución de la crisis estuvieron en la misma línea de las propuestas por Rui Barbosa en 1889. Observamos así una continuidad en las ideas transmitidas por la revista e inferimos el apoyo de Veja a las políticas neoliberales implantadas por el gobierno de Fernando Collor de Melo (20) y su contribución a pensar a la república desde el liberalismo (corriente a la cual adscribían su propietario y director).

\section{La República según la Veja de 1989}

En la edición de la fecha del aniversario de la proclamación (14 de noviembre de 1989), la revista no hace mención a la efeméride en la portada. La tapa, está protagonizada por las elecciones y en una esquina, el anuncio de la caída del muro de Berlín: "El mundo en estado de shock" (14 de noviembre de 1989, Veja, Portada). 


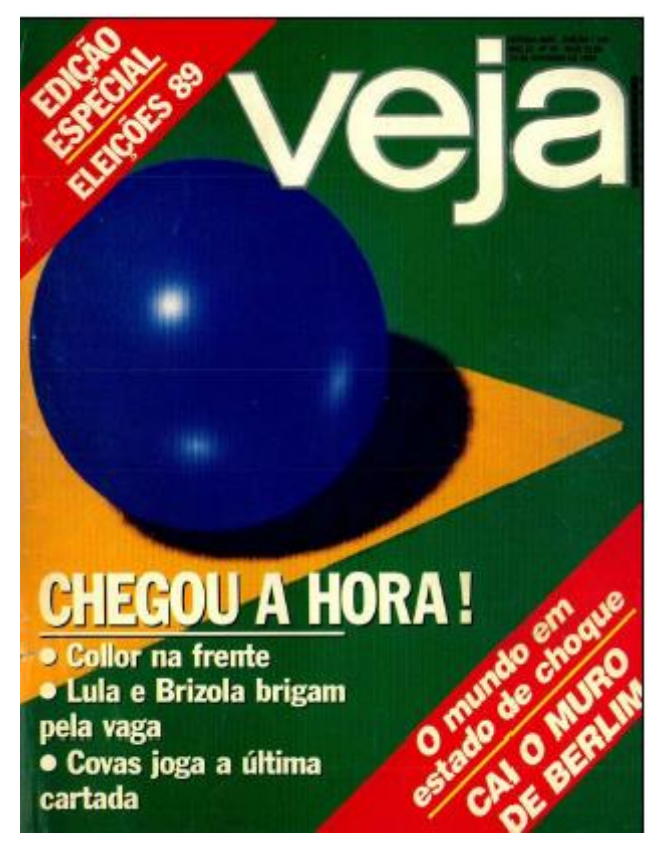

En todo el número, el foco está puesto en las inminentes elecciones presidenciales directas en las que Luiz Inácio Lula da Silva (21) y Fernando Collor de Melo llegarán al balotaje, quedándose el último con la primera magistratura brasileña.

Conviene recordar que esas elecciones se celebraron el 15 de noviembre de 1989, en el día del centenario de la proclamación de la república. Quizás como una forma de revalidarla.

\footnotetext{
$\mathrm{Na}$ quarta-feira desta semana, comemoração de centenário da República, 82 milhões de eleitores estarão no centro de um acontecimento extraordinário: a conquista pelo povo brasileiro do direito de escolher o governo que irá gerir o país nos próximos cinco anos. (...) O resultado é que daqui a pouco, ao tomar a direção das urnas, os eleitores do Brasil terão a oportunidade de zerar uma etapa de sua história -com a mesma naturalidade com que os homens do povo da Alemanha Oriental puderam, na semana passada, passear pelos dois lados do Muro de Berlim e mandar às favas um regime que só existia na ficção. Uma idéia que deu certo (14 de noviembre de 1989), Veja, p.49.
}

Más allá de las evidentes diferencias históricas entre una coyuntura y otra, la revista Veja propone una comparación entre la caída del Muro de Berlín (el 9 de noviembre de ese año) y las elecciones presidenciales brasileñas. En ambos casos, un cambio de época. A su vez, según Veja, para Brasil es el momento de cerrar el sombrío período dictatorial con el comienzo de una nueva república. Tal como se logró cien años atrás con la caída de la monarquía y la instauración de la república. En definitiva, un tiempo de redemocratización.

En este número de la revista, el énfasis está puesto claramente en la idea de democracia. En una idea de ampliación de la democracia, en el sentido de la cantidad de habitantes brasileños 
habilitados para votar. Gracias a la Constitución de 1988, los analfabetos fueron autorizados a participar de los sufragios. Dice Veja, que en las elecciones de 1989 podrían votar el $56 \%$ de los brasileños.

\footnotetext{
Nesta quarta-feira, enfim, eles colhem o resultado do que plantaram participando da eleição presidencial mais ampla, democrática e popular que o Brasil já teve desde a Proclamação da República, exatamente 100 anos atrás. Uma idéia que deu certo (14 de noviembre de 1989), Veja, p.48.
}

Diversos trabajos coinciden en sostener que a partir de 1989 comenzó la etapa de consolidación de la democracia en Brasil (Abreu, 2005; Diniz, 1996; Ansaldi, 1990; Codato, 2005; Menéndez, 2003). En 1985, Neves que pertenecía a una oposición moderada al régimen autoritario, había llegado a la presidencia gracias a los pactos realizados con diversos sectores de las elites y las FFAA (O'Donnell, 1994). El gobierno de Sarney, erigido presidente ante la muerte de Neves, estuvo supeditado al control de unas aun poderosas fuerzas armadas, fue una democracia tutelada. Como se sabe "esa transición se caracterizó por un alto grado de continuidad en el plano de las élites y de las instituciones, persistiendo rasgos del modelo estatista, entre ellos la hipertrofia del Ejecutivo y la fragilidad del sistema de partidos" (Diniz, 1996: 14). La llegada mediante elecciones indirectas también reflejaba que el camino hacia la efectivización de la democracia todavía debía ser desandado.

La ampliación de la democracia la que se refiere Veja es 'democratización', lo que implica la existencia de una competencia abierta por el derecho de conquistar y controlar el gobierno (Abreu, 2005: 53). En términos de Linz y Stepan (1996, citados en Abreu, 2005), la posibilidad de tener un gobierno electo de forma libre y directa, con autoridad para generar nuevas políticas y que los poderes ejecutivo, legislativo y judicial no tengan que dividir el poder con otros organismos.

Ahora bien, en Veja la noción de democracia está íntimamente ligada a la de república, tanto en el número especial del aniversario como en el que salió publicado el 14 de noviembre de 1989, más allá de las discusiones teóricas sobre la definición de estos conceptos (22).

El paso de la monarquía a la república, implicó la democratización del sistema político, a pesar que la elección del primer presidente republicano (Mariscal Deodoro da Fonseca) haya sido por vía indirecta (fue elegido por el Congreso). Además, la abolición de la esclavitud un año antes fue un prolegómeno para esa democratización, en este caso no solo política, sino también civil. No por esto, sin embargo, afirmamos que la primera república brasileña fuera una democracia en términos amplios, pero sí un paso en ese largo camino. Como todo proceso histórico, la democracia (como sistema político y forma de vida) es un proceso lento y prolongado. (23) 
Cien años más tarde, la transición de la dictadura a la democracia vuelve a poner sobre la mesa la idea de república. En tanto esta es entendida como un sistema político que implica la participación del pueblo.

\begin{abstract}
Encerra-se nesta quarta-feira um período extraordinário da História política do Brasil. Nunca antes houve a oportunidade de assistir e participar de uma discussão tão rica a respeito dos problemas do país, do seu presente e de seu futuro. (...) A participação popular extravasou para as ruas e praças, em carreatas e comícios vibrantes. (...) Sabe-se e se pratica a plenitude da vida democrática. Fim de uma etapa memorável (14 de noviembre de 1989), Veja, p.45.
\end{abstract}

La república vuelve a aparecer aquí en las ideas de participación popular y libre como características claves de la vida democrática. Ya no sólo se observa el fortalecimiento de la democracia política, si no, para Veja, de una democracia social donde impera el valor de la libertad. En este sentido nos recuerda a la idea de Tocqueville, quien sostenía que "con la palabra democracia no se quiere, por tanto, nombrar un régimen político sino un estado social, un tipo de sociedad" (Dávila, 2003: 11). Tal tipo de sociedad se ordena alrededor del disenso, el conflicto y el pluralismo (Mouffe, 2006). De aquí, el énfasis que la revista le pone la posibilidad que tuvo el pueblo de salir a las calles, discutir ideas en "un ambiente de libertad absoluta y tranquilidad" (Fim de uma etapa memorável. 14 de noviembre de 1989, Veja, p. 45). Asimismo, la estabilidad asoma como forma de pensar a una república exitosa a largo plazo. Veja resalta que en la historia republicana de Brasil, de los cuarenta presidentes que hubo desde 1889, solo trece fueron elegidos directamente por el electorado, cuatro fueron vices que asumieron la presidencia legalmente, mientras que veintitrés llegaron a la primera magistratura producto de golpes de Estado (Democracia sem provo. 14 de noviembre de 1989, Veja, p. 89).

Quando se examina o futuro, fica contabilidade óbvia. Não será no 10 de março de 1990 quando o sucessor do presidente José Sarney tomará posse, que se poderá falar que o país se tornou uma nação civilizada, onde a democracia faz parte da normalidade. Também não será em 1995, com a posse do sucessor do sucessor de José Sarney. Mas apenas no ano 2000, quando se tudo correr bem, será empostado um presidente herdeiro de uma estabilidade semelhante à de Epitácio Pessoa. Democracia sem provo (14 de noviembre de 1989), Veja, p. 92.

Para Veja, la democracia está asociada no solo a la posibilidad del $56 \%$ de la población brasileña de ejercer su derecho al voto, sino también a la no interrupción de ese derecho durante, por lo menos, diez años. Esa continuidad es vista como estabilidad del sistema democrático y por tanto del fortalecimiento de la república que esa democracia representa. 


\section{Palabras finales}

En este artículo procuramos dar cuenta de las representaciones de la república que la revista Veja transmitió en el número especial por el aniversario de la proclamación. También, tomamos la edición de la fecha más cercana al aniversario como forma de contrastar y reforzar las ideas publicadas en aquella edición especial.

La idea de democracia aparece con fuerza en ambas publicaciones. En la edición aniversario, entendiéndola como parte intrínseca de la nueva república y en el otro número como una reconquista del pueblo luego del interregno dictatorial. De esta manera, se sitúa a la democracia como un sistema opuesto tanto a la monarquía como a la dictadura.

Sobre la relación entre república y democracia, Veja propone pensar a la república desde una democracia ampliada, donde no solo importa la posibilidad de elegir a los representantes sino la libertad que tenga el pueblo para debatir ideas, generar consensos o disensos. La libertad como valor de la democracia es fuertemente ponderado si tenemos en cuenta, además, la coyuntura transicional que vivía Brasil desde 1985.

En la Veja de 1889 se concibe a la república como creencia y como acción. Es un sistema en el que se cree para luchar y actuar por él. Por ejemplo, en la propuesta de achicamiento del Estado que se vislumbra en el discurso de Barbosa. Estas ideas de corte liberal esbozadas a fines del siglo XIX se replican cien años después en las medidas neoliberales tomadas por el gobierno de Collor de Melo en pos de recuperar la economía y las finanzas del país que, hoy sabemos, no hicieron más profundizar la desigualdad en Brasil.

Para la Veja de 1989, entonces, la república también está representada en este tipo de propuestas, corroborando así su posición en el sistema político no sólo como un medio de comunicación, sino desde el punto de vista empresarial y, además en representación de esa elite económica cuyos intereses se vieron beneficiados.

Los símbolos, la forma de representar a un régimen político, en este caso la república, colabora con la construcción de legitimidad de dicho sistema (Carvalho, 2008). En el centenario de la proclamación, ya no parece necesario apelar a la bandera, el himno, a los héroes republicanos o a impulsar la unidad nacional, símbolos a los que sí apeló la dictadura militar y que reprodujeron los medios de comunicación que contribuyeron a la construcción de su legitimidad. La legitimidad de la república en 1989 está anclada en la creencia de que ésta es el mejor camino para lograr una democracia fuerte, popular y estable en Brasil, luego de más de veinte años de gobiernos dictaroriales, a los cuales Veja apoyó, pero que en la coyuntura de la transición, ya no ofrecían los beneficios políticos y económicos que podría prometer el futuro gobierno neoliberal de Collor de Melo. 


\section{Notas}

(1) George Bush (padre), miembro del Partido Republicano, fue el $41^{\circ}$ presidente de los Estados Unidos entre 1989 y 1993, años clave en la historia de su país en tanto se convertiría en la primera potencia mundial luego de la caída de la Unión Soviética en 1991.

(2) Carlos Menem fue presidente de la Argentina entre 1989 y 1999, representando al Partido Justicialista. Durante su presidencia, que comenzó con la crisis hiperinflacionaria de 1989, y bajo el amparo del Consenso de Washington, llevó adelante profundas reformas de corte neoliberal. Privatizaciones de empresas estatales, desregulación de la economía, aumento de impuestos, la Ley de Convertibilidad (que establecía la paridad 1 a 1 entre el peso argentina y el dólar estadounidense) y la reforma Constitucional en 1994 fueron las transformaciones más destacadas.

(3) Alfredo Stroessner gobernó Paraguay entre 1954 y 1989, en una dictadura personalista y de las más largas en América Latina. Perteneciente al tradicional Partido Colorado, Stroessner logró estabilidad gracias a la legitimidad institucional del partido (Soler, 2009). El "stronismo" es conceptualizado como una "modernización conservadora" por la reconfiguración cultural, moral y política que llevó adelante en el Paraguay (Soler, 2012).

(4) Carlos Andrés Pérez fue presidente de Venezuela en dos ocasiones. La primera entre 1974 y 1979, un período marcado por el ingreso de 'petrodólares' debido a la creciente exportación de petróleo en el marco de la crisis del año 1973. Su segunda presidencia, 1989-1993, se caracterizó por las privatizaciones, el quiebre que implicó el Caracazo y los escándalos de corrupción que finalmente lo llevaron a su destitución, previo dos intentos de golpes de estado, uno de ellos perpetrado por Hugo Chávez en 1992.

(5) Tancredo Neves fue el primer presidente civil elegido desde 1964, en las primeras elecciones democráticas luego de una dictadura de veintiún años. Aunque las elecciones no fueron directas, sino mediante junta electoral. Perteneciente al partido opositor a la dictadura, PMDB, Neves tuvo apoyos de amplios sectores durante la campaña electoral. Sin embargo, una enfermedad intestinal que lo llevó a una muerte prematura, le impidió asumir la presidencia, que quedó en manos de José Sarney, el vicepresidente electo, quien venía de las filas del partido oficialista de la dictadura.

(6) José Sarney asumió el cargo de presidente (1985-1989) ante el fallecimiento del presidente electo, Tancredo Neves. Su gobierno no estuvo exento de dificultades. La crisis hiperinflacionaria llevó a la instauración del Plan Cruzado para contener la suba de precios. Más allá de las crisis, su gobierno fue especialmente conocido por llevar adelante la Asamblea Constituyente que culminó con la nueva Constitución de Brasil en 1988. 
(7) Time es una revista de información general fundada por Henry Luce y Briton Hadden. La primera en su género en los Estados Unidos, su país de origen. Su primer número salió publicado en marzo de 1923. Su objetivo era informar a sus ocupados lectores de manera sistemática y concisa acerca de los acontecimientos a nivel local e internacional. La revista está divida en varias secciones que incluyen gran cantidad de artículos cortos. Por el alcance de su circulación, Time se convirtió en la revista más influyente de los Estados Unidos hacia 1927, título que conserva hasta el día de hoy.

(8) El Acta Institucional №5 (Al-5) no tenía fecha de caducidad y con su proclamación el régimen mostró su intención de permanecer en poder, marcando una diferencia con su rol de poder moderador ( $\sin$ tomar el poder) que habían ejercido a lo largo del siglo XX hasta el golpe de 1964. Como consecuencia, se abrió la etapa más represiva y restrictiva de la dictadura, que incluía la censura a la prensa.

(9) http://www.publiabril.com.br/marcas/veja/revista/informacoes-gerais. Consultado el 14 de marzo de 2015.

(10) Mino Carta, periodista italiano de gran reconocimiento en Brasil, fue el primer director de Veja. Durante el período de Carta como director, la revista sufrió la censura previa, presuntamente por su posición crítica respecto del régimen militar.

(11) "Em primeiro lugar, Veja, a grande revista, desempenha um papel político ruim. Seu saldo essencial tem sigo o de apoiar a política do governo. Salvo um período de resistência aos aspectos mais nocivos do regime, quando era editada por Mino Carta, ela tem sido uma revista a serviço de grupos palacianos, com um estilo de jornalismo que tem se deteriorado em função disso" (Raimundo Pereira, colaborador de Veja. Silva 1983, citado en Mira 1997, 123).

(12) Un partido político "es la expresión de un grupo social y nada más que de un solo grupo social. Sin embargo, en determinadas condiciones sociales, algunos partidos representan un solo grupo social en cuanto ejercen una función de equilibrio y de arbitraje entre los intereses del propio grupo y los de los demás grupos y procuran que el desarrollo del grupo representado se produzca con el consentimiento y con la ayuda de los grupos aliados y, en ciertos casos, con el de grupos adversarios más hostiles" (Gramsci, 2008: 29).

(13) Los intelectuales son los "encargados" por el grupo dominante para el ejercicio de las funciones subalternas de la hegemonía social y del gobierno político, esto es: 1] del consenso "espontáneo" dado por las grandes masas de la población a la orientación imprimida a la vida social por el grupo dominante fundamental, consenso que nace "históricamente" del prestigio (y por lo tanto de la confianza) derivado por el grupo dominante de su posición y de su función en el mundo de la producción (Gramsci, 1986: 357).

(14) Sucintamente mencionamos que el Imperio fue la forma de gobierno establecida en Brasil luego de la declaración de independencia 7 de septiembre de 1822, a manos del emperador Pedro I. Entre ese año y 1889, Brasil fue el único país monárquico de la región. Al igual que la 
independencia, la proclamación de la República no implicó luchas libertadoras, sino que ambas instancias se produjeron sin derramamiento de sangre. La República se proclamó el 15 de noviembre de 1889, mediante un golpe de estado de miembros disidentes del ejército liderado por el mariscal Deodoro da Fonseca, derrocando al Emperador Don Pedro II.

(15) Don Pedro II se convirtió en emperador de Brasil a los 5 años de edad, luego de que su padre Pedro I abdicara al trono y regresara a Portugal en 1831. Gobernó Brasil durante 58 años, en los que se destacaron algunos hechos clave en la historia de Brasil como la Guerra de la Triple Alianza (1864-1870) y la abolición de la esclavitud en 1888. Luego de proclamada la República y derrocado el Emperador, el gobierno provisional intimó a la familia imperial a salir del país. El embarque, previsto para el día 17 de noviembre fue adelantado por temor a manifestaciones, lo que implicó que el monarca y su familia tuvieran salir casi como fugitivos. Además de eso, se prohibió a la familia retornar a Brasil y poseer inmuebles en el país. La prohibición fue levantada hacia 1920, por lo que los restos del Emperador y su esposa Teresa Cristina yacen en la catedral de Petrópolis, en el Estado de Río de Janeiro.

(16) Ernesto Geisel fue el tercer presidente de facto de la dictadura brasileña. Su mandato se extendió entre 1974 y 1979. Su gobierno se caracterizó por llevar adelante la llamada 'apertura' del régimen, que guiaría a la transición, aunque finalmente la dictadura se extendió por cinco años más. Además, durante su mandato Geisel debió lidiar con las consecuencias de la crisis del petróleo de 1973, que derivó en profundos problemas económicos para Brasil.

(17) Rui Barbosa fue parte del primer gabinete de ministros una vez proclamada la república. De una larga trayectoria política, como ministro de finanzas, su gestión terminó en una gran crisis económica (la primera de la era republicana) debido a la desmedida emisión de papel moneda.

(18) Para un análisis del régimen oligárquico en América Latina ver Ansaldi (1992).

(19) El ufanismo hace referencia a jactarse de o vanagloriar a un país. En el caso de Brasil, el ufanismo surge del texto Porque me ufano de meu país, escrito por Alfonso Celso en 1908, en el que "demuestra" la superioridad de Brasil en todos sus aspectos. La idea de la grandeza de Brasil ya aparece en los primeros años republicanos. La dictadura militar de 1964, retomó la concepción ufanista a través de la idea de "Brasil potencia", fortalecida por el "milagro económico". En democracia se sigue apelando al ufanismo, ya como una característica propia de la república brasileña.

(20) Fernando Collor de Melo fue Presidente de Brasil entre 1990 y 1992, el primero elegido por voto directo después de la dictadura, por lo que se considera a las elecciones de 1989 un momento clave en la consolidación de la democracia. El gobierno de Collor fue el exponente del comienzo de la aplicación de las políticas neoliberales en su país. En 1992, Collor fue destituido mediante juicio político, acusado de corrupción. 
(21) Luiz Inácio (Lula) da Silva es uno de los líderes políticos más importantes de Brasil. Sus inicios fueron como líder sindical en el marco del 'nuevo sindicalismo' a fines de los años 1970. Es uno de los fundadores del Partido dos Trabalhadores (PT) y en 1989 fue la primera vez que se postuló a la presidencia, llegando a la instancia del balotaje. Se presentó sin éxito en otras dos oportunidades (1994 y 1998) hasta que en 2002 logró ganar las elecciones. Reelecto en 2006, gobernó Brasil entre 2003 y 2010.

(22) No son pocos los autores que han trabajado sobre las nociones de república y democracia, especialmente desde la ciencia política. Solo por mencionar a algunos de los más relevantes, retomamos a Sartori (2007), Dahl (2004), Bobbio (1985 y 1986), O'Donnell (1988), Mouffe (2006), Nun (2000), Rinesi (2015), y por supuesto Rousseau (2011).

(23) Aquí reponemos las ideas de Charles Tilly (1991) sobre la sociología histórica y su análisis de "grandes estructuras, largos procesos y enormes comparaciones".

\section{Bibliografía}

Abreu, A. A. de (2005). A mídia na transição democrática brasileira. Sociologia, problemas e práticas, 48, pp. 53-65.

Ansaldi, W. (1990). Las elecciones de 1989 en Brasil: la fiesta de la democracia entre las perplejidades del presente y las angustias del futuro. Cuadernos del Claeh, $X V(53)$, pp. 23-38.

Ansaldi, W. (1992). Frívola y casquivana, mano de hierro en guante de seda. Cuadernos del claeh, Revista uruguaya de Ciencias Sociales, 17 (segunda serie).

Bobbio, N. (1986). El futuro de la democracia. México: Fondo de Cultura Económica.

Bobbio, N. (1985). La crisis de la democracia y la lección de los clásicos. En Bobbio, N.; Pontara, G. y Seca, S. Crisis de la democracia. Barcelona: Ariel.

Borrat, H. (1989). El periódico, actor del sistema político. Anàlisi, 12, pp. 57-80.

Borrelli, M. (2011). Voces y silencios: la prensa argentina durante la dictadura militar (19761983). Perspectivas de la comunicación, 4(1), pp. 24-41.

Bresser Pereira, L. C. (1978). O colapso de uma aliança de classes. São Paulo: Editora Brasiliense.

Bresser Pereira, L. C. y Nakano, Y. (1991). Hiperinflação e estabilização no Brasil: o primeiro Plano Collor. Revista de Economia Política (octubre-diciembre), 44, pp. 89-114.

Carvalho, J. M. de (2008). A formação das almas. São Paulo: Companhia Das Letras.

Celso, A. (2002). Porque me ufano do meu país. Brasil: Fonte Digital.

Codato, A. (2005). Uma história política da transição brasileira: da ditadura militar à democracia. Revista de Sociologia e Política, 25, pp. 83-106. 
Dávila, L. R. (2003). Tocqueville: reinvención y riesgos de la democracia. Revista Internacional de Filosófica Política, Madrid 22, pp. 5-21.

Diniz, E. (1996). Gobernabilidad, democracia y reforma del estado: los desafíos de la construcción de un nuevo orden en Brasil en los años 90. América Latina, Hoy, 14, pp. 13-21.

Fausto, B. (2010). História do Brasil. São Paulo: Edusp-Editora da Universidade de São Paulo.

Giordano, V. (2017). Derechas, neoliberalismo y estereotipos de género. La revista Veja de Brasil, 1989-1999, Nuevo Mundo Mundos Nuevos, Coloquios, pp. 1-19.

Goldstein, A. (2017). Prensa tradicional y liderazgos populares en Brasil. Raleigh: A Contracorriente (Universidad Estatal de Carolina del Norte).

Gramsci, A. (1986). Cuadernos de la cárcel Tomo 4. México D.F.: Ediciones Era.

Gramsci, A. (2008): Notas sobre Maquiavelo. Buenos Aires: Nueva Visión.

Linz, J. y Stepan, A. (1996). Problems of Democratic Transition and Consolidation. Baltimore y Londres: John Hopkins University Press.

Marradi, A.; Archenti, N. y Piovani, J. I. (2010). Metodología de las ciencias sociales. Buenos Aires: Emecé.

Martins, L. (1994). La 'liberalización' del gobierno autoritario en Brasil. En O’Donnell, G.; Schmitter, P. y Whitehead, L. (compiladores). Transiciones desde un gobierno autoritario. América Latina. Buenos Aires: Paidós.

Menéndez, M. C. (2003). Adaptación estratégica, aversión al riesgo e incertidumbre: el caso de la transición democrática brasileña. Revista Múltipla, Brasília, 9(15), pp. 9-41.

Mira, M. C. (1997). O leitor e a banca de revistas. O caso da Editora Abril. (Tesis de Doctorado). Instituto de Filosofía y Ciencias Humanas, Universidad Estadual de Campinas.

Mouffe, Ch. (2006). Democracia, ciudadanía y la cuestión de la pluralidad. En Álvarez Enríquez L.; San Juan Victoria, C. y Sánchez Mejorada, C. (coordinadores). Democracia y exclusión: caminos encontrados en la Ciudad de México. México: Plaza y Valdéz editores.

Nun, J. (2000). Democracia: ¿gobierno del pueblo o gobierno de los políticos? Buenos Aires: Fondo de Cultura Económica.

O’Donnell, G. (1994). Introducción a los casos latinoamericanos. En O’Donnell, G.; Schmitter, P. y Whitehead, L. (compiladores). Transiciones desde un gobierno autoritario. América Latina. Buenos Aires: Paidós.

O'Donnell, G. (1997). Contrapuntos. Buenos Aires: Paidós.

Pucciarelli, A. (2004). La patria contratista. El nuevo discurso liberal de la dictadura militar encubre una vieja práctica corporativa. En Pucciarelli, A. (Comp.). Empresarios, 
tecnócratas y militares. La trama corporativa de la última dictadura. Buenos Aires: Siglo XXI Editores.

Rangel Martínez, R. y Garmendia Soto Reyes, E. (2012). El Consenso de Washington: la instauración de las políticas neoliberales en América Latina. Política y Cultura, 37, pp. 35-64.

Rautenberg, E. (2011). A revista Veja e as empresas da construção civil (1968-1978). (Tesis de Maestría). Universidad Estadual del Oeste de Paraná, Brasil.

Rinesi, E. (2015). Populismo y republicanismo. Revista Ensambles 3, (primavera), pp. 84-94.

Rousseau, J. J. (2011). Del contrato social. Argentina: Universidad Nacional de General Sarmiento y Universidad Nacional de Córdoba.

Sader, E. (2001). Una democracia sin alma social. El ajuste estructural en América Latina. Costos sociales y alternativas. Buenos Aires: CLACSO, Consejo Latinoamericano de Ciencias Sociales.

Sartori, G. (2007). ¿Qué es la democracia? España: Taurus.

Scarzanella, E. (2016). Abril. Un editor italiano en Buenos Aires, de Perón a Videla. Argentina: Fondo de Cultura Económica.

Sidicaro, R. (1993). La política mirada desde arriba: las ideas del diario La Nación 1909-1989. Buenos Aires: Editorial Sudamericana.

Silva, Carlos Eduardo Lins da (1983): Quinze anos de Veja. Revistas semanais de informação cosolidam sua posição no mercado. Revista Crítica da informação (septiembre).

Souza da Silva, C. L. (2005). Veja: O Indispensável partido neoliberal (1989-2002). (Tesis de Doctorado). Universidad Federal Fluminense/Universidad Estadual del Oeste de Paraná, Brasil.

Skidmore, T. E. (1991), De Castelo a Tancredo. Río de Janeiro: Editora Paz e Terra.

Soler, L, (2009), Dominación política y legitimidad. El stronismo en el contexto de América Latina. Novapolis, Revista de Estudios Políticos Contemporáneos, Germinal, Arandura, Asunción, I(4), Tomo II, pp. 83-105.

Soler, L. (2012). Paraguay: La larga invención del golpe. El stronismo y el orden político paraguayo. Buenos Aires/Montevideo, Imago Mundi Ediciones/CEFIR.

Tilly, Ch. (1991). Grandes estructuras, procesos amplios, comparaciones enormes. Madrid: Alianza Editorial.

Valle, M. Ribeiro do (2012). 1968-2008: O Veja "Way of Life". Intercom-RBCC, 35(2), pp. 129147.

Van Dijk, T. (2002). El análisis crítico del discurso y el pensamiento social. Athenea Digital, 1, pp. 18-24.

Villalta, D. (1 al 5 de septiembre de 2002). O surgimento da revista Veja no contexto da modernização brasileira. INTERCOM-Sociedade Brasileira de Estudos 
Interdisciplinares da Comunicação XXV Congresso Brasileiro de Ciências da Comunicação-Salvador/BA.

Weffort, F. (1989). Incertezas da transição na América Latina. Lua Nova, 16, pp. 5-45. 